\title{
Use of static passive acoustic monitoring to assess the status of the 'Critically Endangered' Baltic harbour porpoise in German waters
}

\author{
Anja Gallus ${ }^{1, *}$, Michael Dähne ${ }^{1,2, *, * *}$, Ursula Katharina Verfuß ${ }^{1}$, Stefan Bräger ${ }^{1,4}$, \\ Sven Adler ${ }^{2,3,5}$, Ursula Siebert ${ }^{2}$, Harald Benke ${ }^{1}$ \\ ${ }^{1}$ German Oceanographic Museum, 18439 Stralsund, Germany \\ ${ }^{2}$ Institute for Terrestrial and Aquatic Wildlife Research (ITAW), University of Veterinary Medicine Hannover, Foundation, \\ 25761 Büsum, Germany \\ ${ }^{3}$ Institute for Biodiversity, University of Rostock, 18057 Rostock, Germany \\ ${ }^{4}$ Present address: The Whale Museum, Friday Harbor, Washington 98250, USA \\ ${ }^{5}$ Present address: Swedish University of Agricultural Sciences, 90183 Umeå, Sweden
}

\begin{abstract}
Harbour porpoise Phocoena phocoena abundance in the Baltic Proper (BP) is at a level where measures for improving the status of this genetically and morphologically discrete population are urgently needed. Without knowledge on seasonal and geographical distribution, a common basis for conservation efforts has been lacking for the past decades. We deployed 22 porpoise detectors from March 2005 until August 2007 in the eastern German Baltic Sea to study seasonal migrations and abiotic factors associated with porpoise presence/absence patterns. Two years of continuous monitoring resulted in 11890 recording days from 21 stations within the BP, with only 207 porpoise-positive days ( $\mathrm{ppd}$ - a day with verified porpoise detection), equaling $1.86 \%$ ppd per month and station over the study period. Data were analysed using generalised additive models to find significantly influencing factors. Detection rates in the BP peaked twice seasonally: once associated with the summer occurrence of animals from the population living mostly in the Belt Sea and once correlated with (1) cold air temperatures and (2) air temperatures lower than water surface temperatures. The latter suggests that porpoises from the BP migrate towards mostly ice-free waters in winter to avoid suffocation. In order to reduce harmful set-netting, conservation measures must be seasonally regulated, at least, or less harmful fishing methods must be implemented. These findings should help to improve the current European anti-bycatch legislation, e.g. regulation EC 812/2004, which is currently under review.
\end{abstract}

KEY WORDS: Phocoena phocoena - Temporal and spatial distribution · Baltic Sea · Generalized additive modelling $\cdot$ Click detector $\cdot$ T-POD

\section{INTRODUCTION}

Harbour porpoises Phocoena phocoena are the only cetacean species regularly occurring and reproducing in the Baltic Sea (Scheidat et al. 2008). Porpoises are protected under European legislation, in particular, by being listed in Annex II and IV of the EU Habitats Directive (92/43/EEC; European Union 1992). These listings require the creation of special areas of conservation (Art. 6) and the establishment of a system of strict protection for the animal species listed (Art. 12) to maintain or allow

\footnotetext{
${ }^{*}$ These authors contributed equally to the manuscript 
them to recover sufficiently to reach a favourable conservation status. Additional obligations for porpoise conservation in the Baltic Sea arise from intergovernmental agreements and their porpoise recovery goals, such as the 'Jastarnia Plan' of the Agreement on the Conservation of Small Cetaceans of the Baltic, North East Atlantic, Irish and North Seas (ASCOBANS 2009) and HELCOM Recommendation 17/2 of the Helsinki Convention (Helsinki Commission 1996). Early last century, harbour porpoises occurred within the Baltic Proper (BP), east of the Darß and Limhamn Sill and adjacent waters (Fig. 1), in fairly high numbers, as indicated by strandings (Skóra et al. 1988), by-catch in fisheries (Skóra \& Kuklik 2003) and direct catch (Kinze 1995). Since the population has declined (reviewed in Koschinski 2001), special measures are needed to protect this apex predator in a fragile ecosystem.

The causes for the decline of harbour porpoises in the BP are still poorly understood. Possible factors include habitat deterioration due to eutrophication, prey depletion due to over-fishing, severe winters with freezing of large parts of the BP (Seinä \& Palosuo 1996) and subsequent die-offs (Koschinski 2001), pollution with chemical toxins such as polychlorinated biphenyls and heavy metals, ship traffic (Koschinski 2001, Jastarnia Group \& Bräger 2009) andprobably most important-non-target by-catch in

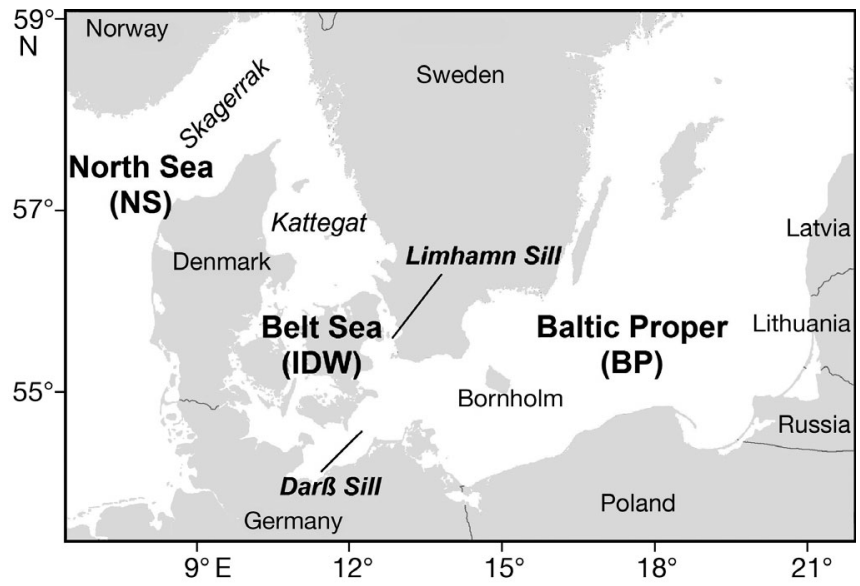

Fig. 1. Overview of the Baltic Sea, excluding the Gulf of Botnia, Finland and Riga. IDW: inner Danish waters

bottom-set gill nets and drift nets (Berggren et al. 2002, ASCOBANS 2009). The European Commission attempted to regulate by-catch of small cetaceans in gill nets (EU Council 2004) by making mandatory (1) the use of acoustic deterring devices (such as pingers) to prevent by-catch in gill nets, (2) dedicated observers to report cetacean by-catch in specified European waters and (3) banning drift nets. Most of the Belt Sea and almost all of the BP, except for ICES (International Council for the Exploration of the Sea) Area 24, however, were excluded from such measures (1 and 2). The use of pingers may not solve the problem in low-density areas (Carlström et al. 2009), because even very low by-catch rates will prevent recovery of Baltic harbour porpoises (Berggren et al. 2002). Construction noise and anthropogenic noise in general probably add a further threat (e.g. Carstensen et al. 2006).

According to genetic and morphological research, 3 distinct populations of harbour porpoises inhabit the Baltic Sea (Figs. 1 \& 2) and adjacent areas: (1) the North Sea (NS) population covering also the Skagerrak and the northern part of the Kattegat, (2) the inner Danish waters (IDW) population in the Kattegat and Belt Seas bordered by the Darß and Limhamn Sills and (3) the BP population around the island of Rügen and northwards to Finland (Berggren et al. 1999, Galatius et al. 2011, Huggenberger et al. 2002, Koschinski 2001, Teilmann et al. 2008, 2011, Wiemann et al. 2010).
Fig. 2. Positions of click detectors (timing-porpoise-detectors, T-PODs) and MARNET measuring platforms (of the German Maritime and Hydrographic Agency) within the study area. Most co-variables were measured at MARNET positions and applied to the nearest T-POD position. There are 2 extensively shallow areas within Pomeranian Bay: the rocky Adlergrund and sandy Odra Bank 
While the population in the North Sea appears to have shifted its distribution south between July 1994 and July 2005 according to the 2 SCANS (Small Cetaceans in the [European] Atlantic and North Sea) surveys (Hammond et al. 2002, SCANS II 2008), the basin-wide abundance has not significantly changed. Healthy status is unlikely, however, for the IDW population (Teilmann et al. 2011) and is most definitely not the case for the BP population. Aerial line transect survey data were collected in an area extending from the south coast of Sweden to Poland and the island of Rügen (Berggren et al. 2002, 2004, L. Hiby \& P. Lovell unpubl. data) in the summers of 1995 and 2002. In 1995, a total of 3 porpoises were sighted, and in 2002 a total of 2 observations of porpoise pods were collected off the south coast of Sweden. From these very few observed animals it was estimated using distance sampling, that 599 porpoises (95\% $\mathrm{CL}=200$ to 3300) inhabited this area in 1995 and approximately 93 groups in 2002 (95\% CL = 10 to 460). Harbour porpoise in the Baltic are usually observed in group sizes between 1 and 2 individuals (e.g. Berggren et al. 2002, Scheidat et al. 2008). The 2002 result is not significantly lower than in 1995, because the confidence bands are very large due to the extremely small sample sizes.

These low abundance estimates, detection rates and high uncertainty caused serious concern about the population status of harbour porpoises in the BP area. Uncertainty is so high that even the survival of this population has been in question at times. Boatbased surveys with passive acoustic methods as well as visual observers were carried out using a towed hydrophone system in 2001 and 2002 (Gillespie et al. 2005). Only 3 acoustic detections were recorded in the western BP (excluding Polish waters) in 2002, and only 1 visual sighting was obtained on effort in Polish waters in 2001. These surveys confirmed the 'Critically Endangered' status of the BP harbour porpoise population as stated by the IUCN Red list (Hammond et al. 2008).

The border between the 2 populations (IDW and BP) was originally assumed to be the salt water inflow barriers into the BP: the Limhamn Sill in the Øresund and the Darß Sill in the Kadet Trench (Huggenberger et al. 2002, Palme et al. 2004). Teilmann et al. (2011) found that some satellite-tagged porpoise in IDW moved east of the island of Rügen even towards Bornholm. They also found that a small proportion of porpoises from the NS and IDW populations briefly resided within the neighbouring population's area, suggesting that some overlap in distributional range may exist. The Baltic Sea is one of the largest brackish water bodies of the world and is prone to freezing in severe winters, which may constitute $11 \%$ of all winters (Seinä \& Palosuo 1996). Ice conditions vary with a salinity gradient from the south-westerly waters of the Belt Sea, dominated by porous ice, up to the north-easterly waters around Finland, Sweden, Russia, Estonia and Latvia, dominated by fast freshwater ice (Granskog et al. 2006).

Harbour porpoises are extremely mobile animals and can travel up to $50 \mathrm{~km} \mathrm{~d}^{-1}$ (Westgate et al. 1995) and swim approximately $7 \mathrm{~km} \mathrm{~h}^{-1}$ (Schulze 1996). Maximum speeds are probably between $16.6 \mathrm{~km} \mathrm{~h}^{-1}$ (Kanwisher \& Sundnes 1965) and $22.2 \mathrm{~km} \mathrm{~h}^{-1}$ (Gaskin et al. 1974), but are unlikely to be sustained over long periods of time.

The use of echolocation click loggers in low-density areas has provided new research opportunities for species such as the vaquita Phocoena sinus (Rojas-Bracho et al. 2006, Jaramillo-Legorreta et al. 2007), the Hector's dolphin Cephalorhynchus hectori (Rayment et al. 2009), as well as its highly endangered sub-species, the Maui dolphin C. hectori maui (Rayment et al. 2011). Since 2002, the German Oceanographic Museum has been carrying out static acoustic monitoring (SAM) of harbour porpoises using click detectors called T-PODs (timing-porpoisedetectors, Chelonia Ltd.) to record the occurrence of these animals continuously within the framework of various research projects (Verfuß et al. 2007, 2008a). Results from these studies suggested strong geographical and seasonal variation in habitat use in the German Baltic Sea west of the island of Rügen. Acoustic detections declined from west to east, increased during spring to peak in summer and declined again in fall. Verfuß et al. (2007) did not show any seasonal variation north and east of the island of Rügen (Pomeranian Bay), the area most probably inhabited by the BP population. Already in 2002, the first version of the Jastarnia Plan of ASCOBANS (2009) outlined the need for more detailed knowledge on the habitat use of the Baltic harbour porpoise.

We conducted large-scale acoustic monitoring with 22 measuring positions to obtain new information on distribution, seasonal and geographic variation, and ecological dependencies of the BP population in German waters. One major aim of the present study was to find possibilities to protect BP porpoises with regard to their geographical and seasonal distribution, a possible habitat partitioning between BP and IDW populations, and to determine whether SAM is an appropriate tool for monitoring this low-density population. 


\section{MATERIALS AND METHODS}

T-PODs are self-contained acoustic data-loggers developed to register echolocation clicks of odontocetes via a hydrophone, filters, a sound processor and battery in a watertight housing tested for up to $150 \mathrm{~m}$ water depth. The T-POD compares the energy content of the porpoise echolocation frequency band, which typically lies around $130 \mathrm{kHz}$ (Au et al. 1999, Kamminga et al. 1999), and a reference band around $90 \mathrm{kHz}$, in real-time. Time of occurrence and duration of possible echolocation clicks are saved to a memory chip. Durations registered are highly correlated with the loudness of the signal and can be regarded as a proxy for amplitude. T-POD detection ranges are smaller than $500 \mathrm{~m}$. Calibration of the TPODs (Dähne et al. 2006, Verfuß et al. 2008b) was conducted before and after the study and once every year to obtain a measure for the variation of instrument sensitivity probably resulting in differences in the amount of recorded clicks. T-POD (Versions 2 to 5) instrument settings are described in Table 1. 'Minimum intensity/sensitivity' was adjusted for individual T-PODs to standardise the detection threshold to $127 \mathrm{~dB}$ re $1 \mu \mathrm{Pa}$ peak-peak. As not all T-PODs could be set to this value, detection threshold and hardware version were also included as co-variables in the modelling process. Furthermore T-PODs were rotated among deployment locations.

Data were downloaded, processed and exported with the proprietary software 'T-POD.exe' Version 7.4

Table 1. Instrument settings used during the study; minimum intensity/sensitivity setting was adjusted for each instrument's detection threshold. Versions 2 and 3 (V2 \& V3) have similar settings; settings for Versions 4 and 5 (V4 \& V5) are different due to adaptation of the hardware by the manufacturer; hence, not all settings are applicable to each version. ++: noise adaption switched on. A and B areas, see Fig. 2

\begin{tabular}{|lccc|}
\hline \multirow{2}{*}{ Setting } & Applicable & \multicolumn{2}{c|}{ T-POD version } \\
& for & V2 \& V3 & V4 \& V5 \\
\hline $\begin{array}{c}\text { Target (A) filter } \\
\text { frequency }\end{array}$ & V2-V5 & $130 \mathrm{kHz}$ & $132 \mathrm{kHz}$ \\
$\begin{array}{c}\text { Reference (B) filter } \\
\text { frequency }\end{array}$ & V2-V5 & $90 \mathrm{kHz}$ & $90 \mathrm{kHz}$ \\
$\begin{array}{l}\text { Selectivity (ratio A/B) } \\
\text { Click bandwidth }\end{array}$ & V2,V3 & 6 & \\
$\begin{array}{l}\text { 'A' integration period } \\
\text { 'B' integration period }\end{array}$ & V2,V3 & Short (10) & \\
$\begin{array}{c}\text { Noise adaptation } \\
\text { Minimum intensity/ } \\
\text { sensitivity }\end{array}$ & V4,V5 & Long (18) & \\
$\begin{array}{c}\text { Scan limit of no. } \\
\text { of clicks logged }\end{array}$ & V2-V5 & Variable & Variable \\
\hline
\end{tabular}

using train detection algorithm Version 3.0. Train detection of likely harbour porpoise vocalisations in all detection classes ('CetHi' to 'very doubtful') was used to find possible click trains within any given $10 \mathrm{~min}$ period. These detections were double-checked visually by trained observers for the presence of harbour porpoise Phocoena phocoena echolocation click sequences and then classified as porpoise, boat, or other sound. The minimum number of automatically classified clicks to be regarded as porpoise was defined to be 5 . The progression of inter-click intervals (ICI) and duration of individual clicks was used for visual classification taking all registered clicks in that time period into account. Automatic detections of possible porpoise origin were rejected (false positives) when (1) ICI did not show a variation in click pattern typical for echolocation click trains (see Amundin 1991, Au 1993, Verfuß et al. 2005, 2009), e.g. an ICI variation in consecutive clicks of up to $\pm 40 \%$; (2) duration was constantly or mostly $<20$ or $>500 \mu \mathrm{s}$; and (3) another source of the automatically detected sounds could be identified (boat engine or sonar, ambient noise) as the likely source of the classified clicks. Only verified click sequences were included in all subsequent analyses. From these detections, the proportion of porpoise positive days (ppd) and porpoise positive hours (pph), defined as the percentage of days and hours with at least 1 porpoise detection, was calculated for each month. These fairly coarse time periods were used to reduce the number of zeros for this low-density dataset, to reduce effects of temporal and spatial autocorrelation and to have no or only small impacts from variations in instrument sensitivity and hardware version.

\section{Geographic distribution and seasonal variation}

A total of 21 recording positions were chosen for deployment: of these, 15 were placed with even spacing in the 2 extensive shallow-water areas Adlergrund and Odra Bank (marked ' $\mathrm{A}$ ' in Fig. 2; water depth: 7 to $26 \mathrm{~m}$ ) under the restrictions of the water and shipping authorities for the Pomeranian Bay. In addition, 5 coastal positions were located between the Arkona cliffs and the Usedom peninsula and another one north of Rügen (marked with ' $\mathrm{B}$ ' in Fig. 2; water depth: 10 to $22 \mathrm{~m}$ ). Finally, 1 position north of the Darß peninsula (marked 'Ref' in Fig. 2; water depth: $11 \mathrm{~m}$ ) was used as a proxy for the occurrence of animals from the IDW population (Verfuß et al. 2007, 2008a). The positioning was consistent with that used by Verfuß et al. (2007), and instruments were deployed approximately 5 to $7 \mathrm{~m}$ below the 
water surface with small cement anchors $(\sim 30 \mathrm{~kg})$ and nylon ropes (diameter: 12 to $14 \mathrm{~mm}$ ) attached to surface markers (diameter: 20 to $40 \mathrm{~cm}$ ). The deployment method is described in more detail in Verfuß et al. (2007, 2008a). For habitat modelling, data from stations (Stns) of Groups A and B were used together. To investigate the hypothesis that IDW animals enter the BP and may mask ecological preferences of BP porpoises, a second model was built from Group A data only. Data were collected from March 2005 to August 2007 (Fig. 3). In February 2006, the devices had to be removed for up to 4 wk to avoid equipment loss during strong formation of ice floes.

Environmental data were derived from 3 MARNET measuring platforms of the German Maritime and Hydrographic Agency, which are located within the study area (Fig. 2; www.bsh.de/en/The_BSH/ Organisation/BSH_at_a_glance/BSH-Flyer.pdf) to monitor water and air temperatures, salinities, weather conditions and other abiotic factors continuously at different water depths.

Paired detections and diel patterns were analysed for Group A positions only to prevent the possible influence or even masking by IDW animals.

\section{Minimum number of groups indicated by paired detections}

Due to the status of the BP population as 'Critically Endangered' (Hammond et al. 2008), it is very important to know whether it is possible that multiple groups of animals use the area at the same time. Finding multiple groups of animals simultaneously in this area would indicate high importance of the area at particular times of the year. If porpoises from the BP move into the area with multiple groups, conservation measures should be taken. For this reason, we tested whether paired detections, i.e. porpoise detections at multiple stations within a period of $<8 \mathrm{~h}$, could originate from the same animal/group. Within $8 \mathrm{~h}$ porpoises can travel around $56 \mathrm{~km}$ while maintaining a swimming speed of $7 \mathrm{~km} \mathrm{~h}^{-1}$. For comparison, the largest distance between T-PODs in the study area was $55 \mathrm{~km}$. The delay between 2 paired detections $(\Delta t)$ was calculated as the time difference between the last positive 10 min section detection on one T-POD and the first on another detector. Using the distance between the 2 positions $(\Delta s)$, a hypothetical minimum swimming speed $(v)$ was calculated.

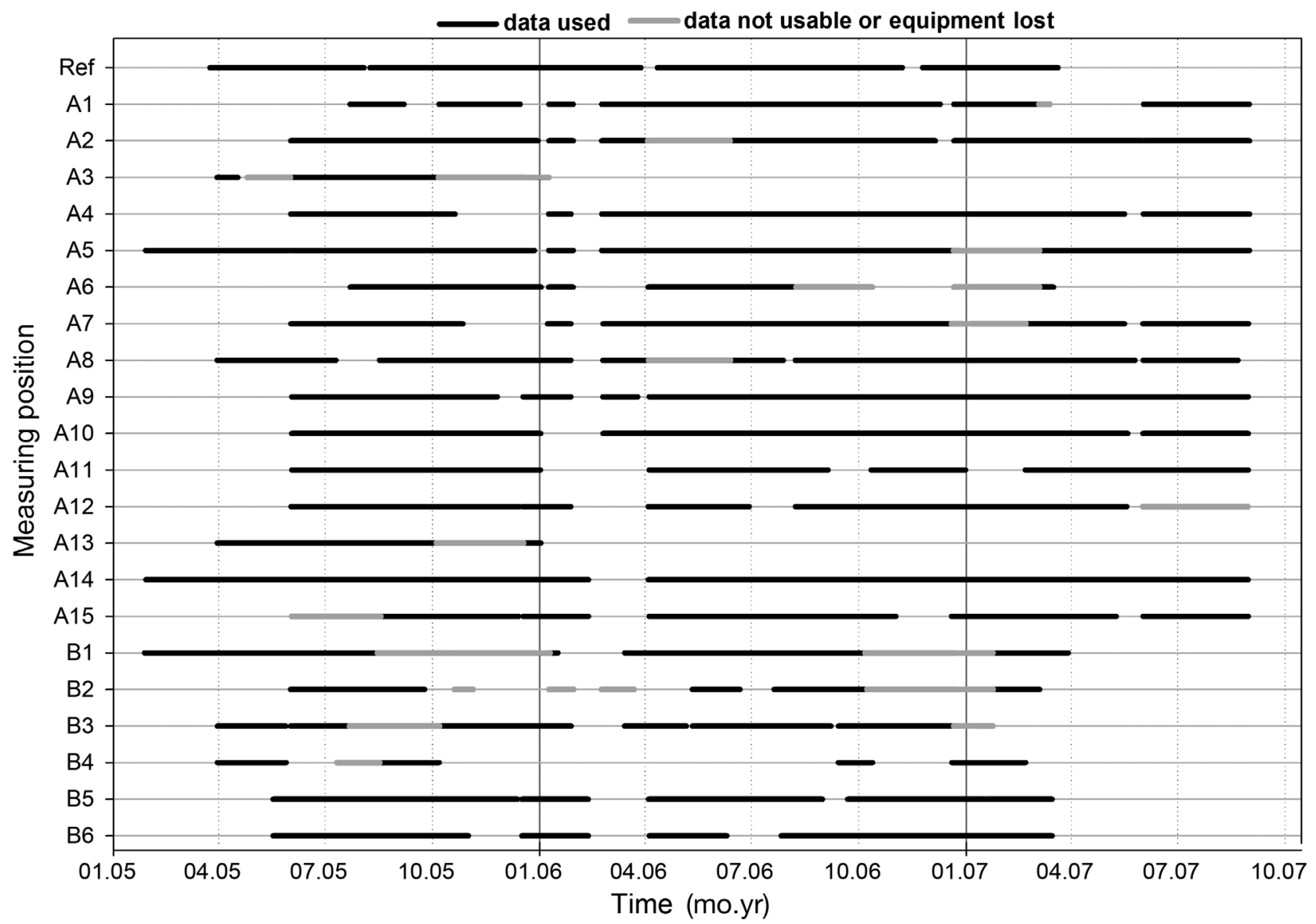

Fig. 3. T-POD deployment period. Site positions as given in Fig. 2 
Paired detections were classified by the resulting swimming speeds as follows: 0 to $7 \mathrm{~km} \mathrm{~h}^{-1}$ : possibly from the same animal/group; 7 to $10 \mathrm{~km} \mathrm{~h}^{-1}$ : likely 2 groups, if the swimming speed was maintained for $>90$ min (i.e. the involved stations were $>10.5 \mathrm{~km}$ apart); 10 to $22 \mathrm{~km} \mathrm{~h}^{-1}$ : likely 2 different animals/ groups, if the time difference was $>45$ min (i.e. the stations were 8 to $17 \mathrm{~km}$ apart); $>22 \mathrm{~km} \mathrm{~h}^{-1}$ : definitely 2 different animals/groups. If more than 2 positions had paired detections (according to these criteria), then all speeds between the positions were calculated in the same fashion.

The number of paired detections might also be used as a metric to be considered for a future abundance estimate. As statistics need to be developed for this metric in order to be used in this fashion, we want to show here that they can support species conservation within very low-density areas, where an abundance estimate using regular statistical methods might not be feasible.

\section{Diel pattern}

Two daily periods were defined. 'Daytime' was the time between sunrise and sunset, and 'nighttime' was defined as the time between sunset and sunrise. The proportion of 'pph' was calculated per daily period and station, and a test was carried out using a pairwise comparison ( $\left.\mathrm{pph}_{\text {nighttime }} \mathrm{vs.} \mathrm{pph}_{\text {daytime}}\right)$ in a generalised linear mixed model with day as a random factor under a quasi-binomial distribution.

\section{Habitat modelling}

To determine the influence of abiotic co-variables and to detect seasonal patterns in harbour porpoise distribution in the Pomeranian Bay, generalised additive models (GAM) were built (Hastie \& Tibshirani 1990, Wood 2006). Following a similar modelling approach of Gilles et al. (2011) with aerial density estimates, we modelled the influence of covariables on the dependent variable ppd per month. Variables were averaged for each month and applied to the nearest neighbouring T-POD position (Table 2).

Because of possible multicollinearity between parameters, the package HH (Heiberger 2012) with the function VIF (variance inflation factor) was used to find possible correlations and exclude variables prior to model-specific selection. Co-variables were excluded when values for the variance inflation factor exceeded 10 (Belsley et al. 1980). When a decision had to be made between 2 correlated variables to be used for further modelling, the co-variable leading to a higher explained deviance and lower GCV (general cross validation) score was preferred.

Table 2. Variables used for habitat modelling. PSU: practical salinity unit; IDW: inner Danish waters; -: not applicable; PS: present study

\begin{tabular}{|c|c|c|c|c|c|c|}
\hline Variable & Measured in/on & Abbreviation & Extra information & Unit & Type & Source \\
\hline \multirow[t]{4}{*}{ Temperature } & Air & AT & - & ${ }^{\circ} \mathrm{C}$ & Cubic spline & MARNET \\
\hline & Surface water & SWT & Sensors at $<10 \mathrm{~m}$ water depth & ${ }^{\circ} \mathrm{C}$ & Cubic spline & MARNET \\
\hline & Bottom water & BWT & Sensors at $>20 \mathrm{~m}$ water depth & ${ }^{\circ} \mathrm{C}$ & Cubic spline & MARNET \\
\hline & $\begin{array}{l}\text { Difference between air } \\
\text { and surface water }\end{array}$ & D-AT-SWT & - & ${ }^{\circ} \mathrm{C}$ & Cubic spline & MARNET \\
\hline \multirow[t]{2}{*}{ Salinity } & Surface & SS & - & PSU & Cubic spline & MARNET \\
\hline & Bottom & BS & $\begin{array}{c}\text { PSU, derived from } \\
\text { impedance measurements }\end{array}$ & PSU & Cubic spline & MARNET \\
\hline Water depth & & WD & - & $\mathrm{m}$ & Cubic spline & PS \\
\hline Latitude and longitude & & teLatLong & - & Degrees & $\begin{array}{l}\text { Tensor product } \\
\text { Wood (2004) }\end{array}$ & PS \\
\hline Detection threshold & $\begin{array}{l}\text { Test tank calibration } \\
\text { for each T-POD } \\
\text { every } 6-12 \text { mo }\end{array}$ & DT & - & - & Cubic spline & PS \\
\hline $\begin{array}{l}\text { Hardware version } \\
\text { of T-PODs }\end{array}$ & & $\mathrm{HV}$ & - & - & Factor & PS \\
\hline Month & & Month & - & - & Cyclic spline & PS \\
\hline Year & & Year & - & - & Cubic spline & PS \\
\hline Porpoise positive days & $\begin{array}{l}\text { At the } \\
\text { station 'Ref' }\end{array}$ & Ref-ppd & $\begin{array}{l}\text { Used as a reference for } \\
\text { the seasonality of the neighbouring } \\
\text { IDW population in German waters } \\
\text { (Verfuß et al. 2007,2008a) }\end{array}$ & $\begin{array}{ll} & - \\
g^{\prime} & \end{array}$ & Cubic spline & PS \\
\hline
\end{tabular}


Calculations were carried out using R 2.14.1 (R Development Core Team 2012) and the package mgcv 1.7.13 (Wood 2004) assuming a quasi-Poisson distribution, as it can cope with zero inflated values (Zuur et al. 2009). To find the most appropriate model, we used backward selection of significant covariables tested via an ANOVA. Models with significantly lower residual deviance were preferred, as well as models with fewer variables and non-significant differences to the model with more variables. After model selection 10-fold cross validation was carried out to estimate the root mean square error of the prediction (RMSEP; Hastie et al. 2009).

The importance of variables was estimated using the $F$-value. Spatial and temporal autocorrelation was assessed using jittered variograms and autocorrelation function plots of the model residuals in R 2.14.1 and the package geoR 1.7.2 (Paulo et al. 2001, Diggle $\&$ Ribeiro 2007) for spatial autocorrelation. No autocorrelation patterns were apparent, probably due to the coarse time period (month) used. Data with $<5$ recording days per month and position were excluded to prevent a bias due to differences in effort.

\section{RESULTS}

Between March 2005 and August 2007, recordings of Phocoena phocoena were made at all 21 stations in the Pomeranian Bay for a total of 11890 d (9282 d for Group A only). Of these, porpoise echolocation click trains were recorded on 207 d (Group A: 132 d), resulting in an overall mean of $1.86 \%$ ppd per station and month (Group A: 1.48\%). For comparison, Stn REF had a mean of $34.02 \%$ ppd per month, ranging from 0 to $83.3 \%$ during 694 d of operation.

\section{Geographic distribution and seasonal variation}

Porpoises were registered at every recording position, except A3 and A13, which had only limited logging time (Fig. 3). With the exception of April and May 2007, porpoises were registered every month. Detections peaked at $19.4 \%$ ppd at Stn A7 in July 2007 and $25.8 \%$ ppd at Stn B2 in August 2006. Maximum average values per station and month for the entire German part of the Pomeranian Bay were obtained in January 2006 with $5.4 \%$ ppd (Group A) and $5.2 \%$ ppd in March 2006 for Group AB.

The seasonal pattern of Group AB positions shows only little variation, but points towards a bimodal distribution of ppd with maxima in the winter (January to March) and again in the summer months (June to August; Fig. 4A). For Group A the variation is even smaller, and the summer peaks are weaker for 2005 and 2006 (Fig. 4B,D). Plotting the ppd per month for the reference position versus surface water temperature (Ref-ppd vs. SWT; Table 2) shows a tight correlation between the variables; Ref-ppd mostly follows the temperatures with a short delay (Fig. 4C). Thus, Ref-ppd appears to follow the same seasonal pattern as the western part of the German Baltic Sea, indicating it to be part of the distribution range of the IDW population (Verfuß et al. 2007). Peak detection rates for Ref-ppd were reached in September 2006, with $83 \%$, and lowest rates occurred generally in winter, with 0 to $7 \%$.

Plotting the mean ppd values of the instrument Groups A and AB (Fig. 4D) shows that a winter peak can be seen in both groups, but that the summer peak is weaker for Group A.

\section{Minimum number of groups indicated by paired detections}

A total of 30 paired detections were observed in the dataset. Ten detections could have originated from the same group, as travel speeds were $<7 \mathrm{~km} \mathrm{~h}^{-1}$. Thirteen pairs of detections were classified to have originated from 2 separate individuals or groups (Table 3). In 2 cases it could even be shown that 3 different porpoise groups were registered. Distances between paired detection varied from 8.5 to $51.8 \mathrm{~km}$ within a time span ranging from 0 min (simultaneous detection) to 5 h $50 \mathrm{~min}$, requiring hypothetical minimum swimming speeds to get from one position to the other ranging from $7.3 \mathrm{up}$ to $37.5 \mathrm{~km} \mathrm{~h}^{-1}$. Most of the paired detections were identified in the winter of 2005/2006 and in the summer of 2007.

\section{Diel pattern}

There was no detectable diurnal pattern between 'nighttime' and 'daytime' vocalisations during the monitoring period ( $\mathrm{p}=0.264$ ) for Group A (Fig. 5).

\section{Habitat modelling}

The variables surface water temperature and bottom water temperature were excluded due to a high VIF in correlation with air temperature. As it appeared counter-intuitive that air temperature should 


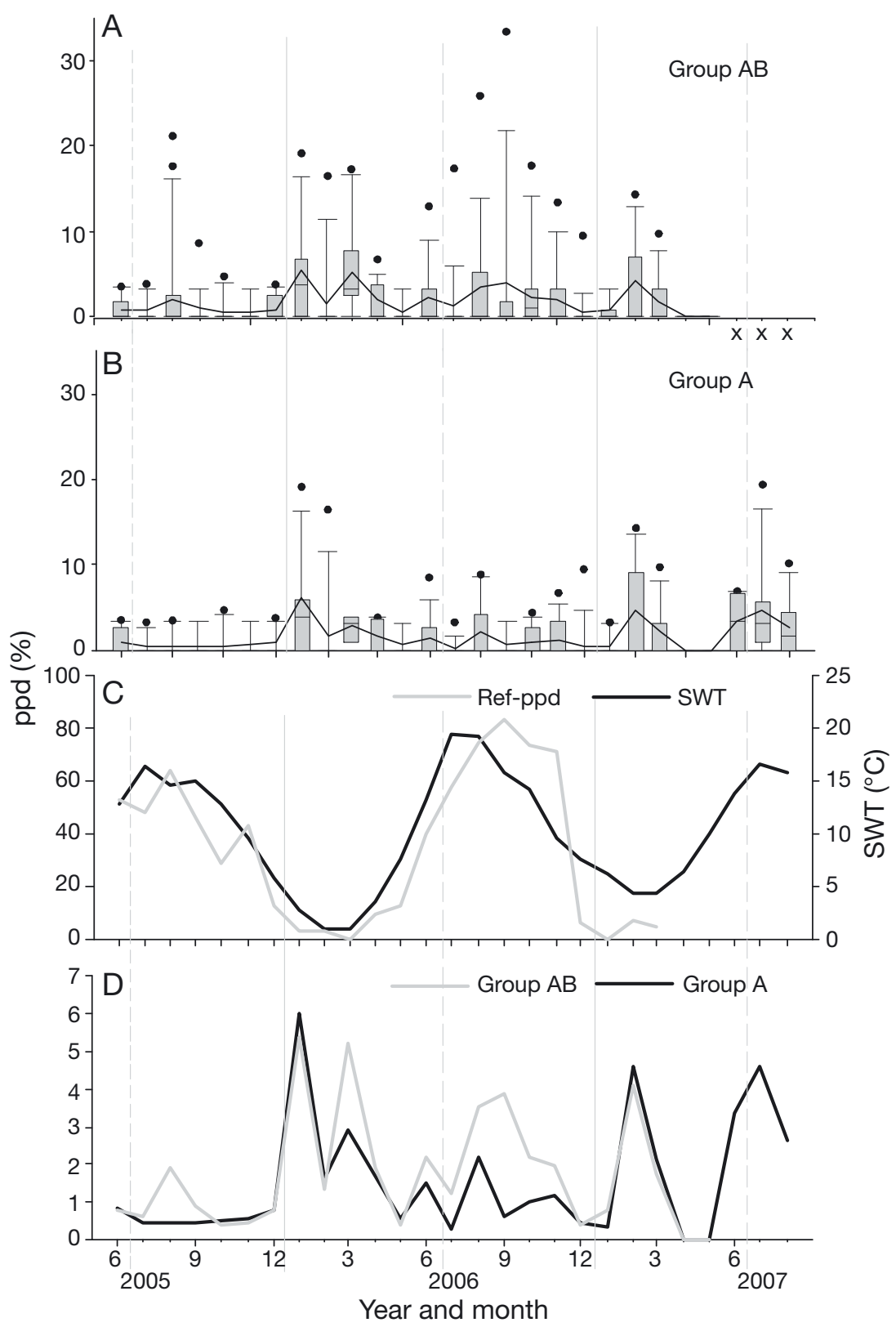

Fig. 4. Phocoena phocoena. Percentage of porpoise positive days (ppd) per month (A) for all stations in Group AB (boxplot shows median, quartiles, 90th and 10th percentiles and outliers) and as a mean (black line) and (B) for all stations in Group A. (C) Average ppd per month at Stn 'Ref' (grey line) and surface water temperature (SWT) at the closest MARNET measuring platform (black line); and (D) comparison of mean ppd per month for Groups A and AB ber of zeros when comparing the difference between model prediction and observed data.

\section{Environmental relationships for all stations north-east of Rügen (Group AB)}

The GAM built with Group AB data showed that water depth, hardware version, month, detection threshold and year were not significant co-variables and were thus excluded during backward selection.

The most important factor in the model (Fig. 6) was the ppd at Ref (Refppd; $F=22.222$, p $=3.36 \times 10^{-6}$ ) followed by air temperature $(F=12.882$, $\left.\mathrm{p} \leq 5.62 \times 10^{-8}\right)$, surface salinity $(F=$ 7.851, $\left.\mathrm{p}=6.64 \times 10^{-4}\right)$, bottom salinity $\left(F=6.483, \mathrm{p}=1.13 \times 10^{-2}\right)$, the tensor product of latitude and longitude (teLatLong; $F=6.108, \mathrm{p}=3.29 \times 10^{-9}$ ) and the difference between air and water surface temperature $(F=4.137$, $\mathrm{p}=6.64 \mathrm{e} \times 10^{-3}$. The model explained $41 \%$ of the deviance $\left(\mathrm{R}^{2}=0.37, \mathrm{n}=\right.$ 419, RMSEP = 3.64).

The model outcome was heavily influenced by Ref-ppd, showing a positive linear correlation. Air temperature shows a positive influence below $4^{\circ} \mathrm{C}$ and is insignificant otherwise, except for a small negative influence around $10^{\circ} \mathrm{C}$. Surface salinity shows a clear influence impacting ppd positively with increasing salinity. Bottom salinity shows a similar pattern. The D-ATSWT shows a negative effect at no or little difference between air and water. The teLatLong showed increasing detections from east to west, with no clear trend in latitude. have a stronger influence on porpoise detections than water temperatures, we tested all model selections with both variables, and air temperature led consistently to a higher explained deviance and lower GCV score. Consequently, only results with air temperature are presented here. Cross validation showed that both models significantly underestimate the influences of co-variables due to the large num-

\section{Environmental relationships for offshore stations (Group A)}

Consistent with the GAM of data from Group AB stations, water depth, hardware version, detection threshold and month were non-significant factors in the model for Group A (Fig. 7). The influences of 
Table 3. Phocoena phocoena. Detections of porpoises at different positions within a short time interval ( $<8 \mathrm{~h})$ and hypothetical traveling speeds $(v)>7 \mathrm{~km} \mathrm{~h}^{-1}$. Date is given in the form dd.mm.yyyy. $\Delta t$ : time difference between detections; $\Delta s$ : spatial distance between detectors; -: not calculable

\begin{tabular}{|c|c|c|c|c|c|c|c|}
\hline Pos. 1 & $\begin{array}{l}\text { Date and time } \\
\text { of detection }\end{array}$ & Pos. 2 & $\begin{array}{l}\text { Date and time } \\
\text { of detection }\end{array}$ & $\begin{array}{c}\Delta t \\
(\mathrm{~h}, \min )\end{array}$ & $\begin{array}{c}\Delta s \\
(\mathrm{~km})\end{array}$ & $\begin{array}{c}V \\
\left(\mathrm{~km} \mathrm{~h}^{-1}\right)\end{array}$ & $\begin{array}{c}\text { Minimum no. } \\
\text { of groups }\end{array}$ \\
\hline A12 & $13.12 .200519: 49$ & A4 & 13.12 .2005 20:49 & $1 \mathrm{~h}$ & 26.9 & 26.9 & 2 \\
\hline A14 & 04.01.2006 03:29 & A12 & 04.01.2006 03:59 & $30 \min$ & 12 & 24.0 & 2 \\
\hline A8 & $10.01 .200603: 29$ & A6 & $10.01 .200605: 19$ & $1 \mathrm{~h} 50 \mathrm{~min}$ & 29.7 & 16.27 & \\
\hline A8 & $10.01 .200603: 29$ & A2 & $10.01 .200605: 39$ & $2 \mathrm{~h} 10 \mathrm{~min}$ & 36.7 & $16.9\}$ & 3 \\
\hline A6 & 10.01.2006 05:19 & $\mathrm{A} 2$ & $10.01 .200605: 39$ & $20 \mathrm{~min}$ & 12.5 & 37.5 & \\
\hline A5 & $17.01 .200601: 19$ & $\mathrm{~A} 2$ & $17.01 .200602: 29$ & $1 \mathrm{~h} 10 \mathrm{~min}$ & 8.5 & 7.3 & $1-2$ \\
\hline A15 & $17.04 .200607: 59$ & A11 & $17.04 .200608: 29$ & $30 \min$ & 12.4 & 24,8 & 2 \\
\hline $\mathrm{A} 2$ & 02.03.2007 03:39 & A14 & 02.03.2007 09:29 & 5 h $50 \mathrm{~min}$ & 51.6 & 8.9 & 2 \\
\hline A10 & 07.06.2007 16:19 & A8 & 07.06.2007 17:29 & $1 \mathrm{~h} 10 \mathrm{~min}$ & 10.1 & 8.7 & $1-2$ \\
\hline A1 & 28.06.2007 22:09 & A2 & 28.06.2007 22:09 & $0 \mathrm{~h}$ & - & - & \\
\hline A1 & 28.06.2007 22:09 & A7 & 29.06.2007 01:09 & $3 \mathrm{~h}$ & 26.6 & 8.9 & 3 \\
\hline $\mathrm{A} 2$ & 28.06.2007 22:19 & A7 & 29.06.2007 01:09 & $3 \mathrm{~h}$ & 30.3 & 10.7 & \\
\hline A4 & 29.06.2007 06:59 & A11 & 29.06.2007 08:19 & $1 \mathrm{~h} 20 \mathrm{~min}$ & 31.8 & 23.9 & 2 \\
\hline
\end{tabular}

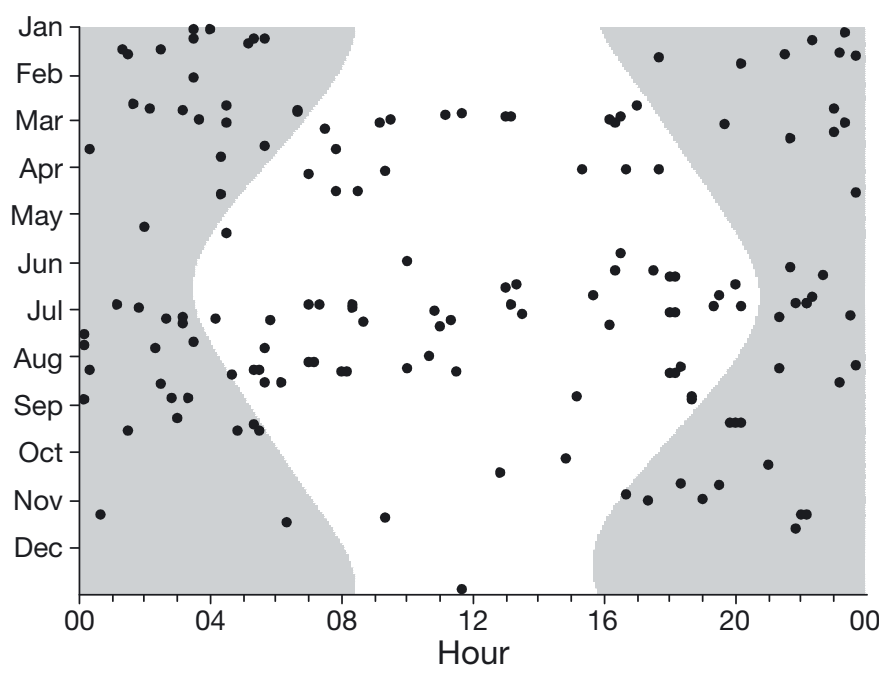

Fig. 5. Diurnal rhythm of detections (within 10 min bins, indicated by dots) in Pomeranian Bay (Group A). Grey areas are nighttime, and white areas are daytime

Ref-ppd, surface salinity and bottom salinity were not significant. The most important factors were the differences between years $(F=39.963, \mathrm{p}=7.32 \times$ $\left.10^{-10}\right)$, followed by D-AT-SWT $(F=11.855, \mathrm{p}=6.39 \times$ $\left.10^{-4}\right)$, teLatLong $\left(F=4, \mathrm{p}=4.91 \times 10^{-4}\right)$ and air temperature $(F=3.742, \mathrm{p}<0.015)$. The resulting model explains $27.9 \%$ of the deviance $\left(\mathrm{R}^{2}=0.166, \mathrm{n}=387\right.$, RMSEP = 3.1).

The variable year shows a clear positive relation (Fig. 7). D-AT-SWT still explains much of the deviance. There is a clear positive effect when air temperature is lower than surface water temperature, and negative effect when slightly above zero. In addition, low air temperatures of $<2^{\circ} \mathrm{C}$ also have a positive effect on the ppd per month. In cases when air temperature is lower than surface water temperature while air
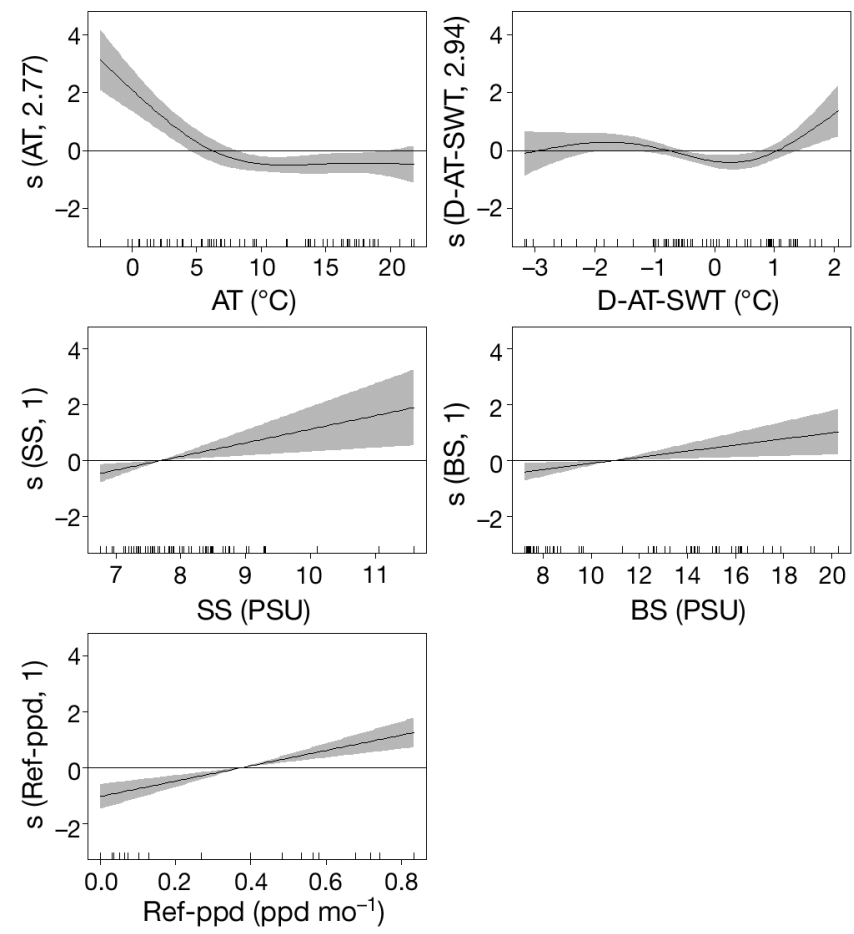

Fig. 6. Results of generalised additive models from stations in Group AB. Shown are the estimated smoothing splines (black line) for each significant variable in the backward selected model together with its 95\% confidence limits (CLs, grey shaded areas) and estimated degrees of freedom (in brackets, $y$-axis). The horizontal black line at a $y$-value of zero indicates in which $x$-values a significant relationship with a factor was estimated. If the CLs are above or below the zero line the variable influences the model positively or negatively. Abbreviations as in Table 2

temperature is $<2^{\circ} \mathrm{C}$, the effects accumulate. The effect of teLatLong does not show a clear geographical trend, but explains much of the variance. 

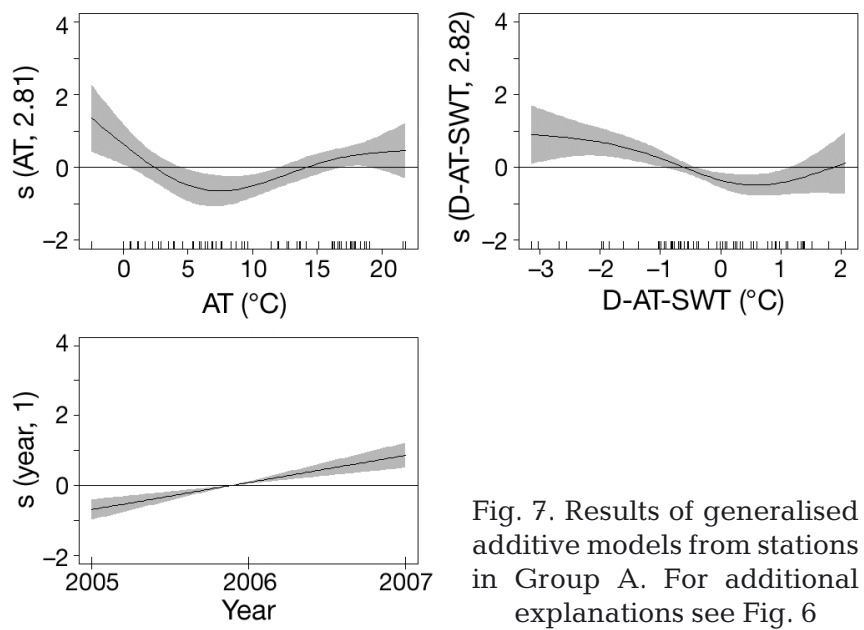

Fig. 7. Results of generalised additive models from stations in Group A. For additional explanations see Fig. 6

\section{DISCUSSION}

The BP harbour porpoise Phocoena phocoena population is 'Critically Endangered' (Hammond et al. 2008). Hence, a better understanding of seasonal migrations, geographic distribution and abundance of these animals is needed in adapting conservation measures. Previous research projects attempted to study habitat use and to estimate the abundance of this population with standard line transect surveys either from airplanes (Hammond et al. 2002, Berggren et al. 2004, L. Hiby \& P. Lovell unpubl. data) or with visual observers and a towed hydrophone array from ships (Gillespie et al. 2005). None of these studies have succeeded in reliably estimating the abundance of porpoises in the Baltic due to extremely low sighting rates resulting in high confidence limits, but they proved that BP porpoises are highly endangered. We did not focus on estimating abundance, but succeeded in describing seasonal patterns and habitat use with 207 porpoise detections within a long-term study period.

The dataset presented here has low detection rates due to the low abundance of porpoises within the area. Detections were reviewed by visual inspection to ensure that only confirmed porpoise events were included in subsequent data analysis. Nevertheless, low detection rates lead to high model errors due to a high impact of zeros. Hence, all conclusions presented here have to be regarded as first results based on the best available methods.

The confirmation of several separate porpoise groups being registered within short times by pairing detections in a relatively small area is an important finding for the definition of critical areas to protect porpoises at certain times of the year. The detection radius of T-PODs has been suggested to be considerably smaller than $500 \mathrm{~m}$ at the $127 \mathrm{db}$ re $1 \mu \mathrm{Pa}$ peakpeak (pp) detection threshold (Kyhn et al. 2008) and may not be extrapolated over a $>350 \mathrm{~m}$ radius. Effective detection ranges are between $\sim 32$ and $\sim 67 \mathrm{~m}$ for all click trains with detection thresholds of $125 \mathrm{~dB}$ re $1 \mu \mathrm{Pa}$ pp according to the form of analysis conducted by Kyhn et al. (2012). Hence, confirming that up to 3 groups of porpoises were present close to the monitoring stations could indicate that even more groups might have been present within the general area without being detected. As this part of the Baltic Sea is considered to be part of the distributional range of the BP population (Koschinski 2001, Huggenberger et al. 2002, Palme et al. 2004), all paired detections can be treated as BP registrations. To avoid by-catch during times with high porpoise occurrence, we suggest employing alternative fishing methods to gill nets, such as fish traps, as also proposed in the Jastarnia Plan (ASCOBANS 2009). Using acoustic harassment devices aims to exclude harbour porpoise from set-netting areas (Carlström et al. 2009). Exclusion from important habitats, however, may reduce the fitness and survival of the population. Due to spatiotemporal associations of porpoises and gill net fisheries (Herr et al. 2009), the use of an alternative gear instead of gill nets is desperately needed to reduce by-catch.

No obvious diurnal pattern was detected. Carlström (2005) showed diurnal patterns for highdensity areas possibly linked to increased foraging activity during night. Patterns may vary depending on preferred prey species, habitat and season, as well as deployment and water depth; however, no such study has yet been conducted within the BP.

The GAMs for both data groups (of combined nearand offshore, and offshore stations alone, respectively) showed significant correlations with various factors. While the GAM of Group A (offshore stations) reacted mainly towards inter-annual differences and D-AT-SWT, as well as the parameter air temperature alone, the model of Group AB (all stations combined) showed a high impact of Stn 'Ref'. Its detections very probably represented mostly animals from the neighbouring IDW population that distribute during spring, summer and autumn throughout the areas west and north of Rügen (Verfuß et al. 2007, 2008a, Gilles et al. 2008, Scheidat et al. 2008). This is supported by findings from Denmark; animals tagged in Danish waters, most probably from the IDW population, usually stayed in Danish and western German waters - only a few strayed briefly into the BP near the southern coast of Sweden and in the 
waters near Bornholm (Teilmann et al. 2011). We therefore conclude that data from near-shore stations on the east coast of Rügen have a high impact on the model of Group $A B$, adding the strong influence of migrating IDW animals that are registered in summer at these stations. Thus, the few detections of BP individuals with differing ecological preferences may hardly influence the model. This hypothesis is of course weakened by the fact that we cannot distinguish the 2 populations acoustically; theoretically, underlying ecological variables may hence cause both populations to migrate similarly. Nevertheless, genetic and morphologic differences have already been shown for the 2 populations, and physiological differences and adaptation to the less saline Baltic Basins are probable and would result in different ecological preferences.

As the influence of Stn 'Ref' was not significant in the model of Group A stations, there appeared to be fewer or no detections of IDW animals among these stations, and any summer peak in the offshore data may be due to a few IDW animals taking advantage of periods with increased prey availability as proposed by Scheidat et al. (2008). The influence of the factor 'year' might be biased by not covering the full year of 2007 and having fewer stations being recorded in the beginning of 2005.

The difference between air and water surface temperature is one of the strongest factors at Group A (offshore) stations, which suggests that BP porpoises remaining in the BP during winter, while IDW porpoises migrate westwards, are probably responding to the temperature gradient. We hypothesise that they move into ice-free waters to avoid confinement and possible suffocation due to ice cover in cold winters. This is supported by higher detection rates during low temperatures at both groups of stations. Once the temperature drops to a certain level, porpoises from the north-eastern parts of the BP might continue to migrate towards the saltier waters farther southwest. During summer, however, animals from the IDW might also use the area east of Rügen, when they appear to disperse throughout all parts of the German Baltic Sea. Therefore, BP porpoises appear to have a seasonal pattern of area use alternating with IDW animals. When including data influenced by IDW animals, population-dependent effects may thus be masked.

Surface and bottom salinity have an effect on the data of Group AB stations. This result underpins the findings of Edrén et al. (2010) who noted a large influence of bottom salinity on tagged animals in Danish waters. Salinity was not significant in Group
A, possibly pointing to different factors driving seasonal migrations for the 2 populations.

Cross validation showed that both models have a high model error and underestimated the importance of model factors when comparing the distribution of errors. Important information for a better understanding of habitat utilisation is therefore still missing, mainly due to low detection rates and ecological variables not incorporated into the model.

Nevertheless, the differences presented in habitat use add important information to the on-going conservation discussion. Distinct populations have genetical (Wiemann et al. 2010) and morphological differences (Huggenberger et al. 2002), but also differ in their ecological preferences, as presented here. Our dataset shows that porpoises in the German BP are scarcely encountered. It thus confirms that porpoises of the BP have become rare and are seriously endangered. Nevertheless, the existence of a BP population still appears to be evident in the different seasonal patterns as it is migrating south-westward into German waters, especially in cold winters. In the absence of detailed knowledge about the spring, summer and autumn distributions of this population, we support the employment of a large-scale use of SAM to an extended area of potentially preferred habitats in the BP, as is currently in progress through an EULIFE+ project called 'Static Acoustic Monitoring of Baltic Harbour Porpoises' (www.SAMBAH.org).

\section{CONCLUSIONS}

Static acoustic monitoring of a small part of the distributional range of porpoises Phocoena phocoena in the BP has enabled us to draw conclusions about the spatial and temporal distribution of harbour porpoises in this low-density area. This was not possible with previous visual abundance estimates. In winter, porpoises from the BP most probably move into the saltier German waters (less prone to freezing). Porpoises appear to predict ice-forming conditions via the empirical difference of surface water and air temperature or this co-variable serves as a proxy for another process that was not modelled. Although our data suggest that the distribution range of the IDW and BP populations possibly overlap geographically, the 2 populations appear to be separated by their temporal distribution pattern.

This implies a direct opportunity for conservation measures, because now - for the first time - data on the temporal and spatial distributions of BP porpoise are available for German waters. Acoustic detection 
rates are low, indicating that the BP population is currently extremely small and at risk of extinction. Conservation actions must be taken immediately to have an effect. Therefore, European legislation such as by-catch regulation EC 812/2004 (EU Council 2004) needs to be improved immediately to ban the use of gill nets in critical parts of the $\mathrm{BP}$, at least at certain times of the year. Other measures such as the use of pingers may not prevent anthropogenic mortality sufficiently and leave Baltic harbour porpoises at further risk.

Acknowledgements. We thank the German Federal Agency for Nature Conservation (BfN) for funding the Jastarnia Research Project (Research Grant FKZ80486011 - K1). Supplementary projects were funded by the German Ministry for the Environment, Nature Conservation and Nuclear Safety (FKZ0329946C) and the BfN (FKZ80285260). The crews of the vessels 'Seefuchs' and 'Palaemon', as well as the coast guard, the water police and the water and shipping authorities provided essential support during fieldwork. Thanks also to D. Machoczek of the German Maritime and Hydrographic Agency (BSH) for access granted to the MARNET data, and to C. Honnef for continuous support during the field work as well as for many helpful discussions. For the critical inspection of the raw datasets we thank K. Krügel and I. Giannikos. D. Tode and A. Kirsch provided administrative support for the project. Considering the difference between air and water temperatures as a co-variable was an ingenious idea from A. Gilles for which we thank her. S. Würtz and A. Gilles gave comments on an earlier version of this manuscript. We thank them and 4 anonymous reviewers for helpful suggestions that greatly improved the paper. Last, but not least, we thank N. Tregenza for developing such a marvellous research tool, for answering all of our questions, for frequent troubleshooting and for his goodhumoured comments. This article is dedicated to the memory of Wolfgang Dinter, who lived for the conservation of marine mammals.

\section{LITERATURE CITED}

Amundin M (1991) Sound production in odontocetes with emphasis on the harbour porpoise Phocoena phocoena. PhD thesis, University of Stockholm, Stockholm

ASCOBANS (Agreement on the Conservation of Small Cetaceans on the Baltic and North Seas) (2009) Recovery plan for Baltic harbour porpoises 'Jastarnia Plan' (2009). Available at: www.ascobans.org/pdf/ASCOBANS_JastarniaPlan_MOP6.pdf (accessed 11 October 2011)

$\mathrm{Au}$ WWL (1993) The sonar of dolphins, Springer-Verlag, New York, NY

Au WWL, Kastelein RA, Rippe T, Schooneman NM (1999) Transmission beam pattern and echolocation signals of a harbour porpoise (Phocoena phocoena). J Acoust Soc Am 106:3699-3705

Belsley DA, Kuh E, Welsch RE (1980) Regression diagnostics: identifying influential data and sources of collinearity. John Wiley, New York, NY

Berggren P, Ishaq R, Zebühr Y, Näf C, Bandh C, Broman D (1999) Patterns and levels of organochlorines (DDTs,
PCBs, non-ortho PCBs and PCDD/Fs) in male harbour porpoises (Phocoena phocoena) from the Baltic Sea, the Kattegat-Skagerrak Seas and the West Coast of Norway. Mar Pollut Bull 38:1070-1084

> Berggren P, Wade PR, Carlström J, Read AJ (2002) Potential limits to anthropogenic mortality for harbour porpoises in the Baltic region. Biol Conserv 103:313-322

Berggren P, Hiby L, Lovell P, Scheidat M (2004) Abundance of harbour porpoises in the Baltic Sea from aerial surveys conducted in summer 2002. Working paper SC/56/SM7 presented to the Scientific Committee of the International Whaling Commission, July 2004, Sorrento

> Carlström J (2005) Diel variation in echolocation behaviour of wild harbor porpoises. Mar Mamm Sci 21:1-12

> Carlström J, Berggren P, Tregenza NJC (2009) Spatial and temporal impact of pingers on porpoises. Can J Fish Aquat Sci 66:72-82

Carstensen J, Henriksen OD, Teilmann J (2006) Impacts of offshore wind farm construction on harbour porpoises: acoustic monitoring of echolocation activity using porpoise detectors (T-PODs). Mar Ecol Prog Ser 321: 295-308

Dähne M, Verfuß UK, Diederichs A, Meding A, Benke H (2006) T-POD test tank calibration and field calibration. In: Leeney RH, Tregenza NJC (eds) Workshop: Static Acoustic Monitoring of Cetaceans; 20th Annual meeting of the European Cetacean Society, 2-7 April, Gdynia, Poland. ECS Newsl 46 Spec Issue):34-36

Diggle PJ, Ribeiro PJ Jr (2007) Model based geostatistics. Springer, New York, NY

Edrén SMC, Wisz MS, Teilmann J, Dietz R, Söderkvist J (2010) Modelling spatial patterns in harbour porpoise satellite telemetry data using maximum entropy. Ecography 33:698-708

EU (European Union) Council (2004) Verordnung (EG) Nr. 812/2004 des Rates vom 26.04.2004 zur Festlegung von Maßnahmen gegen Walbeifänge in der Fischerei und zur Änderung der Verordnung (EG) Nr. 88/98. Available at: http://eur-lex.europa.eu/LexUriServ/site/de/oj/2004/ 1_150/1_15020040430de00120031.pdf (accessed 27 October 2011)

European Union (1992) Council Directive 92/43/EEC of 21 May 1992 on the conservation of natural habitats and of wild fauna and flora. Available at: http://eur-lex.europa. eu/LexUriServ/LexUriServ.do?uri=CONSLEG:1992L0043: 20070101:EN:PDF (accessed 19 October 2011)

Galatius A, Kinze CC, Teilmann J (2011) Population structure of harbor porpoises in the greater Baltic region: evidence of separation based on geometric morphometric comparisons. Report to ASCOBANS Jastarnia group. Available at: www.ascobans.org/pdf/ASCOBANS_JG7 Report_withAnnexes.pdf (accessed 27 May 2012)

Gaskin DE, Arnold PW, Blair BA (1974) Phocoena phocoena. Mamm Species 42:1-8

Gilles A, Herr H, Lehnert K, Scheidat M, Siebert U (2008) Harbour porpoises - abundance estimates and seasonal distribution patterns. In: Wollny-Goerke $\mathrm{K}$, Eskildsen K (eds) Marine mammals and seabirds in front of offshore wind energy. Teuber Verlag \& GWV Fachverlage, Wiesbaden, p 19-36

Gilles A, Adler S, Kaschner K, Scheidat M, Siebert U (2011) Modelling harbour porpoise seasonal density as a function of the German Bight environment: implications for management. Endang Species Res 14: 157-169 
Gillespie D, Berggren P, Brown S, Kuklik I and others (2005) Relative abundance of harbour porpoises (Phocoena phocoena) from acoustic and visual surveys of the Baltic Sea and adjacent waters during 2001 and 2002. J Cetacean Res Manag 7:51-57

Granskog M, Kaartokallio H, Kuosa H, Thomas DN, Vainio J (2006) Sea ice in the Baltic Sea - a review. Estuar Coast Shelf Sci 70:145-160

Hammond PS, Berggren P, Benke H, Borchers DL and others (2002) Abundance of harbour porpoise and other cetaceans in the North Sea and adjacent waters. J Appl Ecol 39:361-376

Hammond PS, Bearzi G, Bjørge A, Forney K and others (2008) Phocoena phocoena. In: IUCN 2011, IUCN Red List of threatened species, Version 2011.1. Available at: www.iucnredlist.org (accessed 27 October 2011)

Hastie TJ, Tibshirani RJ (1990) Generalized additive models. Chapman \& Hall/CRC, London

Hastie TJ, Tibshirani RJ, Friedman JH (2009) The elements of statistical learning: data mining, inference, and prediction, 2nd edn. Springer-Verlag, New York, NY

Heiberger RM (2012) HH: Statistical analysis and data display: Heiberger and Holland. R package version 2. 3-17 http://CRAN.R-project.org/package $=\mathrm{HH}$

Helsinki Commission (1996) Protection of harbour porpoise in the Baltic Sea area. HELCOM Recommendation 17/2 adopted 12 March 1996. Available at: www.helcom.fi/ Recommendations/en_GB/rec17_2/ (accessed 11 October 2011)

Herr H, Fock HO, Siebert U (2009) Spatio-temporal associations between harbour porpoise Phocoena phocoena and specific fisheries in the German Bight. Biol Conserv 142: 2962-2972

Huggenberger S, Benke H, Kinze CC (2002) Geographical variation in harbour porpoise (Phocoena phocoena) skulls: support for a separate non-migratory population in the Baltic Proper. Ophelia 56:1-12

> Jaramillo-Legorreta A, Rojas-Bracho L, Brownell RL Jr, Read AJ, Reeves RR, Ralls K, Taylor BL (2007) Saving the vaquita: immediate action, not more data. Conserv Biol 21:1653-1655

Jastarnia Group, Bräger S (2009) Decline of the harbour porpoise (Phocoena phocoena) in the southwestern Baltic Sea. HELCOM Indicator Fact Sheets (ASCOBANS) 2009. Available at: www.helcom.fi/BSAP_assessment/ifs/archive /ifs2009/en_GB/HarbourPorpoise/?_u4.highlight=decline of the harbour porpoise (accessed 27 October 2011)

Kamminga C, Engelsma FJ, Terry RP (1999) An adult-like sonar wave shape from a rehabilitated orphaned harbour porpoise (Phocoena phocoena). Ophelia 50:35-42

Kanwisher J, Sundnes G (1965) Physiology of a small cetacean. Hvalråd Skr 48:45-53

Kinze CC (1995) Exploitation of harbour porpoises (Phocoena phocoena) in Danish waters: a historical review. Rep Int Whal Comm Spec Issue 16:141-153

Koschinski S (2001) Current knowledge on harbour porpoises (Phocoena phocoena) in the Baltic Sea. Ophelia 55:167-197

Kyhn LA, Tougaard J, Teilmann J, Wahlberg M, Jørgensen PB, Bech NI (2008) Harbour porpoise (Phocoena phocoena) static acoustic monitoring: laboratory detection thresholds of T-PODs are reflected in field sensitivity. J Mar Biol Assoc UK 88:1085-1091

Kyhn LA, Tougaard J, Thomas L, Duve LR and others (2012) From echolocation clicks to animal density-acoustic sampling of harbor porpoises with static dataloggers. J Acoust Soc Am 131:550-560

Palme A, Laikre L, Ryman N (2004) Population genetics of harbour porpoise in Swedish waters. Report 5419, Swedish Environmental Protection Agency, Stockholm

Paulo J, Ribeiro PJ Jr, Diggle PJ (2001) geoR: a package for geostatistical analysis. R-News 1(2):15-18

R Development Core Team (2012) R: a language and environment for statistical computing. R Foundation for Statistical Computing, Vienna. Available at: www.Rproject.org

$>$ Rayment W, Dawson S, Slooten L (2009) Trialling an automated passive acoustic detector (T-POD) with Hector's dolphins (Cephalorhynchus hectori). J Mar Biol Assoc UK 89:1015-1022

Rayment W, Dawson S, Scali S, Slooten L (2011) Listening for a needle in a haystack: passive acoustic detection of dolphins at very low densities. Endang Species Res 14: 149-156

Rojas-Bracho L, Reeves RR, Jaramillo-Legorreta A (2006) Conservation of the vaquita Phocoena sinus. Mammal Rev 36:179-216

SCANS II (2008) Small cetaceans in the European Atlantic and North Sea. Final report to the European Commission under Project LIFE04NAT/GB/000245. Sea Mammal Research Unit, Gatty Marine Laboratory, University of St Andrews, St Andrews

> Scheidat M, Gilles A, Kock KH, Siebert U (2008) Harbour porpoise Phocoena phocoena abundance in the southwestern Baltic Sea. Endang Species Res 5:215-223

Schulze G (1996) Die Schweinswale. Westarp Wissenschaften, Magdeburg

Seinä A, Palosuo E (1996) The classification of the maximum annual extent of ice cover in the Baltic Sea 1720-1995, based on materials collected by Risto Jurva (winters 1720-1940) and the material of the Ice Service of the Finnish Institute of Marine Research (winters 19411995). Merentutkimuslaitoksen 27:79-91

Skóra KE, Kuklik I (2003) Bycatch as a potential threat for harbour porpoise (Phocoena phocoena) in Polish Baltic Waters. NAMMCO Sci Publ 5:303-315

Skóra KE, Pawliczka I, Klinowska M (1988) Observations of the harbour porpoise (Phocoena phocoena) on the Polish Baltic coast. Aquat Mamm 14:113-119

Teilmann J, Sveegaard S, Dietz R, Petersen IK, Berggren P, Desportes G (2008) High density areas for harbour porpoises in Danish waters. NERI Tech Rep No. 657 , National Environmental Research Institute, University of Aarhus, Aarhus

Teilmann J, Sveegaard S, Dietz R (2011) Status of a harbour porpoise population - evidence of population separation and declining abundance. In: Sveegaard S (author) Spatial and temporal distribution of harbor porpoises in relation to their prey. PhD thesis, Aarhus University, Aarhus, p 73-84

Verfuß UK, Miller LA, Schnitzler HU (2005) Spatial orientation in echolocating harbour porpoises (Phocoena phocoena). J Exp Biol 208:3385-3394

Verfuß UK, Honnef CG, Meding A, Dähne M, Mundry R, Benke H (2007) Geographical and seasonal variation of harbour porpoise (Phocoena phocoena) presence in the German Baltic Sea revealed by passive acoustic monitoring. J Mar Biol Assoc UK 87:165-176

Verfuß UK, Honnef CG, Meding A, Dähne M, Adler S, Kilian A, Benke H (2008a) The history of the German Baltic Sea 
harbour porpoise acoustic monitoring at the German Oceanographic Museum. In: Wollny-Goerke K, Eskildsen K (eds) Marine mammals and seabirds in front of offshore wind energy. Teubner Verlag \& GWV Fachverlage, Wiesbaden, p 41-56

Verfuß UK, Dähne M, Diederichs A, Benke H (2008b) Applications and analytical methods for T-POD development in environmental impact studies for wind farms: comparability and development of standard methods. In: Evans PGH (ed) Proceedings of the Workshop on 'Wind farms and marine mammals, 21st annual meetings of the European Cetacean Society, April 22nd-25th 2007, San Sebastian, Spain. ECS Spec Pub Ser 49:27-31

Verfuß UK, Miller LA, Pilz PKD, Schnitzler HU (2009) Echolocation by two foraging harbor porpoises (Phocoena phocoena). J Exp Biol 212:823-834

Editorial responsibility: Ana Cañadas, Madrid, Spain
Westgate AJ, Read AJ, Berggren P, Koopmann HN, Gaskin DE (1995) Diving behaviour of harbour porpoises, Phocoena phocoena. Can J Fish Aquat Sci 52:1064-1073

Wiemann A, Andersen LW, Berggren P, Siebert U and others (2010) Mitochondrial control region and microsatellite analyses on harbour porpoise (Phocoena phocoena) unravel population differentiation in the Baltic Sea and adjacent waters. Conserv Genet 11:195-211

Wood SN (2004) Stable and efficient multiple smoothing parameter estimation for generalized additive models. J Am Stat Assoc 99:673-686

Wood SN (2006) Generalized additive models - an introduction with R. Chapman \& Hall/CRC, Boca Raton, FL

Zuur AF, Ieno EN, Walker NJ, Saveliev AA, Smith GM (2009) Mixed effects models and extension in ecology in R. Springer Science + Business Media, New York, NY

Submitted: January 30, 2012; Accepted: July 5, 2012 Proofs received from author(s): September 13, 2012 